\title{
IDENTIFICAÇÃO DE DEPÓSITOS FLUVIAIS E DESCONECTIVIDADES ANTRÓPICAS NO BAIXO CURSO DO RIO UNA - PE
}

\author{
IDENTIFICATION OF FLUVIAL DEPOSITS AND ANTHOPIC DISCONNETIVITY IN THE LOWER REACH UNA RIVER-PE
}

\section{RESUMO}

Houve a identificação dos tipos de depósitos fluviais existentes no baixo curso do rio Una, como também desconectividades antrópicas, uma vez que estas influenciam na configuração dos depósitos, bem como na dinâmica fluvial. Utilizouse o primeiro estágio da proposta dos estilos fluviais (BRIERLEY e FRYIRS, 2005), relativa à categorização de confinamento de vale como fator primário da morfologia do canal, a partir disso, foi possível identificar trechos de canais onde são encontrados depósitos fluviais. Foram identificadas feições, através de imagens do PE3D e das atividades de campo, sendo realizado um mapeamento de detalhe destes depósitos. Por fim, foi localizada os principais elementos de desconectividades antrópicas presentes no baixo curso do rio Una, buscando associar como estes podem modificar a dinâmica natural do canal, obrigando-o a buscar novos níveis de base e ajustes.

Palavras-chave: Rio Una. Dinâmica fluvial. Depósitos fluviais. Desconectividades. Unidades Geomórficas.

\section{ABSTRACT}

There was the identification of the types of river deposits existing in the lower course of the river Una, as well as anthropic disconnectivities, since these influence the configuration of the deposits, as well as the river dynamics. The first stage of the fluvial styles proposal was used (BRIERLEY and FRYIRS, 2005), relating to the categorization of valley confinement as the primary factor of the channel morphology. From this, it was possible to identify stretches of channels where river deposits are found. Features were identified through PE3D images and field activities, and a detailed mapping of these deposits was carried out. Finally, the main elements of anthropic disconnectivity present in the lower course of the Una River were located, seeking to associate how they can modify the natural dynamics of the channel, forcing it to seek new base levels and adjustments.

Keywords: Una River. Fluvial dynamics. Fluvial deposits. Disconnectivity. Geomorphic Unit.

\author{
Carla Suelania da Silva ${ }^{\text {a }}$ \\ Demerson Flávio da Silva ${ }^{\text {a }}$ \\ Deandro Diomério João dos \\ Santos ${ }^{\text {a }}$ \\ (D) Osvaldo Girão ${ }^{a}$ \\ ${ }^{a}$ Universidade Federal de Pernambuco \\ (UFPE), Recife, PE, Brasil
}

DOI: $10.12957 /$ geouerj.2020.33248

Correpondência:

csuelania.geografia@gmail.com

Recebido em: 19 mar. 2018

Revisado em: 30 jun. 2020

Aceito em: 6 out.2020 


\section{INTRODUÇÃO}

A pesquisa em questão tem como principal objetivo identificar as diferentes formas de deposição fluvial e mapear as principais desconectividades antrópicas presentes no baixo curso do rio Una, o qual possui um ambiente característico de vale lateralmente não confinado, com presença de planícies de inundação continuas, que proporcionam uma compreensão da dinâmica fluvial e geomorfológica dessa paisagem.

O comportamento de um canal fluvial pode variar bastante diante de eventos de grande entrada de energia, atrelado a isso, as desconectividades antrópicas acrescentam um fator cambiante a mais no sistema fluvial. Portanto, integrar esses conhecimentos ao processo de planejamento em bacias hidrográficas podem trazer contribuições significativas para os Comitês de Gestão.

O rio Una, seria um exemplo da necessidade de integração desses conhecimentos, visto em junho de 2010 a bacia hidrográfica do Una ter sofrido com um megaevento pluvial, onde houveram grandes perdas materiais e de vidas. Logo, o reconhecimento relativo aos processos geomorfológicos fluviais pode se constituir em ferramenta útil para ser utilizada no gerenciamento e planejamento da bacia hidrográfica em questão.

\section{Os depósitos fluviais e as des(conectividades)}

Os depósitos fluviais configuram-se em morfologias que podem surgir em qualquer ponto de canal. Todavia, a maior parte do material é depositado nas seções onde o gradiente do canal é pequeno, ou onde há mudanças bruscas no gradiente e na profundidade, assim como na velocidade de escoamento. De acordo com Moraes Novo (2008) os depósitos fluviais podem ser classificados em dois tipos, baseado no local onde ocorrem, podendo estes ser identificados como de canal ou de planície de inundação.

A partir da análise de autores como Mackin (1937); Fisk (1947); Happ, Rittenhouse e Dobson (1940); Leopold e Wolman (1957); Wolmam e Miller (1957) citados por Christofoletti (1981), diante das dificuldades para englobar a variabilidade dos ambientes deposicionais, estes são classificados a partir de critérios práticos três grupos: 1. Depósitos em canais fluviais; 2. Depósito nas margens; 3. Depósitos em bacia de decantação.

Para Moraes Novo (2008) os depósitos do canal podem ser classificados em depósitos transitórios, intermitentes e de preenchimento. Sobre as morfologias dos depósitos de margens, como os de planície de inundação que, de acordo Christofoletti (1981), corresponde à faixa do vale fluvial, composta por sedimentos aluviais que circundam o curso de água, que é periodicamente inundado pelas águas de transbordamento proveniente do rio. Já os depósitos de bacias de inundação são áreas pobremente drenadas, planas, sem movimentação topográfica, localizadas nas adjacências das faixas aluviais (CHRISTOFOLETTI, 1981). 
Nos depósitos de canais, mais precisamente os emersos, objeto da pesquisa deste artigo, estes se constituem em barras e ilhas fluviais, de acordo com Rocha e Souza Filho (2005), sendo as barras fluviais menores em relação ao nível do rio, com menor estabilidade, e não apresentam vegetação arbórea. Já as ilhas fluviais podem representar a evolução de barras por agradação, além da presença de vegetação arbórea consolidada. As ilhas podem ser também caracterizadas por depósitos do centro de canal que se formam pela redução de competência de escoamento da carga sedimentar de um rio (CHRISTOFOLETTI, 1981; GUERRA e GUERRA, 1997; MORAES NOVO, 2008).

Sobre as áreas de planícies aluviais em trechos de baixa declividade, de acordo com Christofoletti (1981), estas podem se destacar a partir de morfologias como canais de meandros abandonados, cujo processo de gênese dar-se com a travessia seguindo a depressão topográfica, corte de pedúnculo e avulsão. Estes que configuram e levam a formação da tipologia destas unidades geomorfológicas fluviais.

Estes depósitos que compõem determinadas paisagens fluviais são resultados de processos de acumulação de sedimentos em pontos do canal que, por conseguinte, quando observados em planta e analisada sua configuração de vale, tem-se a perspectiva dos estilos fluviais que contribuem como uma metodologia para estudos morfológicos e processuais da Geomorfologia Fluvial.

A tipologia de estilos fluviais foi criada por Brierley e Fryirs (2000; 2005). De acordo com os referidos autores, estilos fluviais (river styles) representam uma metodologia de classificação de segmentos de rio, que dispõem um conjunto comum de características geomorfológicas. Com o objetivo de analisar e classificar as diversas formações geomórficas encontradas no decorrer do canal, a partir da delimitação de trechos, podese encontrar ambientes diversos, cabendo a esta metodologia observá-los para categorizar com base em sua tipologia (LIMA e MARÇAL, 2013).

Os estilos fluviais buscam agregar ferramentas para a construção de cenários com o objetivo de realizar uma análise integrada do sistema fluvial, permitindo identificar as relações entre processos e formas, uma vez que esses ocupam um lugar na configuração da paisagem da bacia de drenagem, onde o rio manifesta-se como elemento relevante deste sistema (BRIERLEY e FRYIRS, 2005).

Para essa classificação é importante destacar duas questões principais: a planta do canal e o tipo de confinamento do vale, pois estas características auxiliam, respectivamente, na análise da energia do fluxo, granulometria, sedimentos, tipos de transportes, formas fluviais e extravasamento, ou não, de um canal (BRIERLEY e FRYIRS, 2005).

Salienta-se que o confinamento do canal é um elemento determinante nos estilos fluviais, e está diretamente ligado às formas e processos de um trecho do rio. A partir do padrão de confinamento do vale é possível estabelecer se ocorre, ou não, extravasamento do fluxo além do canal, isso determina se em períodos 
de alta vazão o fluxo permanece dentro do canal ou extravasa, possibilitando o processo de sedimentação (SOUZA, 2012).

Segundo Brierley e Fryirs (2005) para efetivação da proposta de estilos fluviais é importante considerar o confinamento do vale, a planta do canal, as unidades geomórficas e a textura do leito. Para o presente artigo, é apresentado o confinamento do vale, consistindo como a primeira etapa para essa tipologia, pois o mesmo tem um importante papel na morfologia fluvial. A configuração do vale atua como fator primário na formação das zonas processuais de fonte, de transferência e acumulação de sedimentos, como também para os processos geomórficos ao longo do canal. Importante ressaltar que diferenças na largura do vale podem modificar as formas de erosão e deposição, como também controlar os fatores relacionados a inundações (BRIERLEY e FRYIRS, 2005).

O comportamento do canal fluvial vai variar de acordo com sua configuração de vale, ou seja, vale confinado, parcialmente confinado e lateralmente não confinado apresentam capacidade de ajustes na morfologia do canal, deposição de sedimentos, granulometria do material de leito, transporte e acumulação de sedimentos de forma distinta. Desse modo, a compreensão do tipo de confinamento do canal torna-se relevante para o entendimento da relação processo-resposta dos rios diante, por exemplo, de forte entrada de energia (BRIERLEY e FRYIRS, 2005).

Ainda sobre os estudos da geomorfologia fluvial, como complementação aos estilos fluviais na presente pesquisa, surge, a "posteriori", a proposta teórica e metodológica da conectividade da paisagem, frisando as pesquisas sobre transferência de matéria e energia pelos elementos, vigente em um sistema (SOUZA, 2014). Utilizando-se a partir da abordagem sistêmica nos estudos da Geografia, especificamente da Geomorfologia, vem ganhando destaque por trabalhar com as questões da complexidade existente na sistematização da paisagem.

De acordo com Brunsden e Thornes (1979), a concepção de conectividade na geomorfologia fluvial advém do desenvolvimento da definição de sensitividade da paisagem. Nesse contexto, Harvey (2002), afirma que o sistema pode ser apresentado em três configurações: coupled, decoupled e not coupled (ligado, desligado e não-ligado). Sendo o coupled quando o sistema tiver um fluxo de matéria e energia entre seus compartimentos. O decoupled, seria uma interrupção efêmera na transmissão, por consequência de alguma barreira na qual poderá ser rompida no futuro. O not coupled, onde não ocorreria interação e circulação entre os compartimentos por uma ou mais descontinuidade no sistema. (BRIERLEY, FRYIRS e JAIN, 2006).

A relação de conectividade e desconectividade podem ser desenvolvidas em níveis de enfoque dentro do sistema fluvial, ou seja, de escalas, sendo estas locais, zonais e regionais (SOUZA, 2014). A local se configura nas ligações internas, isto é, são as transferências existentes dentro de uma ou entre duas zonas próximas no 
ambiente fluvial, como, por exemplo, entre a encosta e o canal. As zonais fazem as ligações de cunho mais geral entre duas zonas, enquanto a regional perpassa de elementos dos quais afetam todo o sistema. Assim, Harvey (2002) ratifica que na escala maior (local) os condicionantes das ligações relacionam-se as mudanças ambientais que afetam a transmissão, todavia as escalas menores (zonal e regional), o controle seria por alterações climáticas e tectônicas, respectivamente.

Brierley, Fryirs e Jain (2006), salientam que no sistema fluvial a noção de ligação está associada à transmissão de matéria e energia pelos compartimentos da paisagem. Dessa maneira incorpora a concepção de conectividade, na qual é compreendida como a perspectiva de matéria e energia entre os compartimentos dos quais se integram.

Segundo Fryirs e Brierley (2013), a conectividade da paisagem como ligações pode ter três dimensões espaciais: verticais, laterais e longitudinais. As longitudinais são as ligações de transporte de sedimentos ao longo do curso entre o sistema de canais. As laterais refletem a relação da rede hidrográfica e a paisagem adjacente ao canal como o canal-encosta e canal-planície de inundação. Por conseguinte, as ligações verticais seriam as interações, em uma escala maior de análise, entre a água e o sedimento em meio a superfície e a subsuperfície. (BRIERLEY, FRYIRS e JAIN, 2006; FRYIRS e BRIERLEY, 2013).

No espaço, as ligações podem sofrer interrupções nos fluxos de matéria e energia do sistema fluvial, levando os compartimentos da paisagem a uma desconectividade. Estes bloqueios são denominados buffers (retentores), barriers (barreiras/obstáculos), blankets (coberturas) e boosters (impulsionadores) (BRIERLEY e FRYIRS, 2005; FRYIRS et al., 2007a). Salienta-se que estas desconectividades podem barrar ou diminuir a transmissão, ou ainda ajudar e aumentar a transferência, como ocorre com os boosters (impulsionadores) (SOUZA, 2014).

Os Buffers são formas que impedem a entrada de sedimentos nos canais, já os barriers são bloqueios constituídos dentro dos canais. Os blankets são interrupções ligadas às interações de cunho vertical e o próprio retrabalhamento dos materiais transportados. Por fim, os boosters promovem o aumento da propagação de matéria e energia no sistema (BRIERLEY, FRYIRS e JAIN, 2006; FRYIRS, BRIERLEY et al., 2007a; HOOKE, 2003; BLANTON e MARCUS, 2009; FRYIRS, 2013).

Além dos obstáculos naturais existem, os de cunho antrópico, como barragens, estradas, dentre outros, edificados pela ação humana. Estes barramentos, a exemplo das barragens, obstruem o transporte de sedimento, mas o material em suspensão pode ultrapassar essas barreiras, mesmo com o aumento da deposição a jusante dos barramentos (FRYIRS, BRIERLEY, et al., 2007a). Segundo Fryirs (2013), essas formas desconectantes modificam o balanço de sedimentação, o que pode gerar alterações de quilômetros de distância a montante ou jusante em relação à desconectividade (DREW, 2005; KASAI, BRIERLEY et al., 2005). 
Entretanto, os bloqueios podem atuar de maneira distinta em relação à magnitude e frequência da entrada de energia e matéria no sistema fluvial. Por isso, esse contexto está relacionado com a sensitividade da paisagem, ou seja, ofeedback dos eventos e os limiares de mudança (BRUNSDEN, 2001; THOMAS, 2001).

Logo, a conectividade encontra-se associada à velocidade e transmissão de mudanças, em sistemas altamente conectados. Os efeitos das alterações se manifestam de forma relativamente rápida, contudo, em meios desconexos, as modificações são absorvidas ou eliminadas, parcialmente ou completamente (FRYIRS et al., 2007a; SOUZA, 2014).

\section{MATERIAL E MÉTODOS}

Área de estudo

O estado de Pernambuco possui dois destinos principais para os rios com nascentes em seu território: o rio São Francisco e o oceano Atlântico. As drenagens que escoam para o rio São Francisco, são denominadas de rios interiores, e as que se direcionam para o Atlântico, rios litorâneos. As principais bacias litorâneas são o Goiana, Capibaribe, Ipojuca, Sirinhaém, Una e Mundaú, frisando que alguns rios possuem seus limites fora do estado de Pernambucano, como Una, Mundaú, Ipanema e Moxotó (APAC, 2017).

A pesquisa foi desenvolvida na Unidade de Planejamento Hídrico (UPH5), correspondente a bacia hidrográfica do rio Una (Figura 1), estando localizada nas regiões fisiográficas do Agreste e Zona da Mata Sul pernambucana, nas coordenadas geográficas $08^{\circ} 17^{\prime} 14^{\prime \prime}$ e $08^{\circ} 55^{\prime} 28^{\prime \prime}$ de latitude sul, e $35^{\circ} 07^{\prime} 48^{\prime \prime}$ e $36^{\circ} 42^{\prime} 10^{\prime \prime}$ de longitude oeste (APAC, 2017).

A bacia hidrográfica do rio Una tem os limites hidrográficos: ao sul com a bacia do rio Mundaú, o grupo de bacias de pequenos rios litorâneos e grupo de bacias de pequenos rios interiores; ao norte com as bacias dos rios Ipojuca e Sirinhaém e o grupo de bacias de pequenos rios litorâneos; a leste com oceano Atlântico, a bacia do rio Sirinhaém e o grupo de pequenos rios litorâneos, e a oeste com os rios Ipojuca e Ipanema (CONDEPE/FIDEM, 2006). 


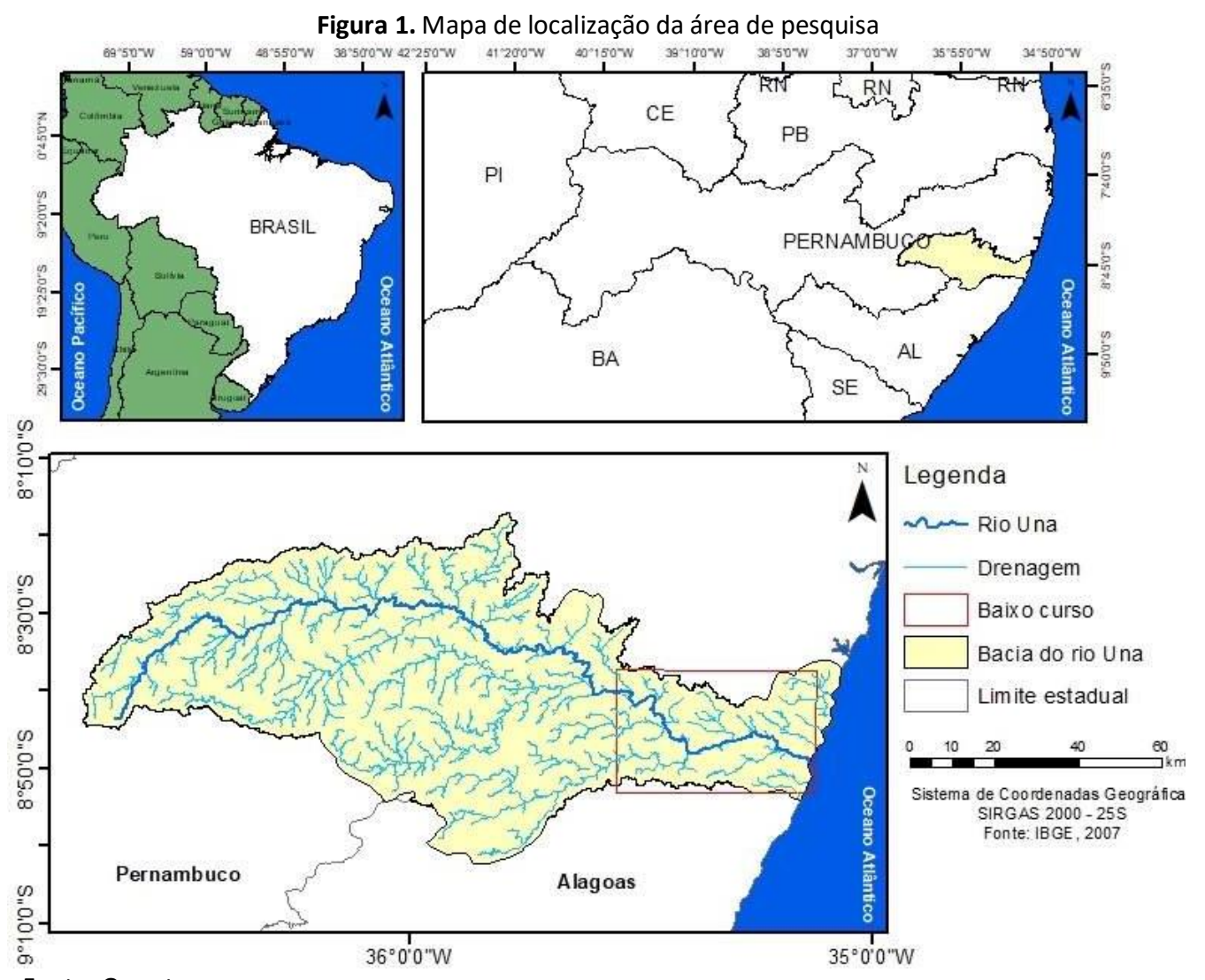

Fonte: Os autores.

O rio Una nasce na serra da Boa Vista, a cerca de 900 metros de altitude no município de Capoeiras na mesorregião do Agreste de Pernambuco, apresentando um caráter intermitente até o município de Altinho, quando passa a ser considerado perene até sua foz no município de São José da Coroa Grande, percorrendo 290 quilômetros (APAC, 2017).

A geologia da bacia é construída majoritariamente por rochas cristalinas e cristalofilianas do Éon PréCambriano, a área sedimentar se encontra nos depósitos areno-argilosos de aluviões atuais, além de poucos resquícios da Formação Barreira. (CONDEPE/FIDEM, 2006). A região de estudo possui seu relevo dividido em quatro grandes compartimentos, sendo eles: a planície fluvial, planalto sedimentar litorâneo, piemonte da Borborema e o planalto da Borborema (SILVA e SILVA, 2016).

A planície fluvial se encontra no baixo curso e tem cotas abaixo de 100 metros com os compartimentos divididos em faixa costeira e colinas. O planalto sedimentar litorâneo tem colinas e tabuleiros dissecados e está no baixo e médio curso da bacia. O Piemonte e o planalto da Borborema se encontram no médio e alto curso, os quais detém relevo de contas altimétricas maiores que 400 a 1000 metros, com superfícies aplainadas (CONDEPE/FIDEM, 2006; SILVA e SILVA, 2016).

A dinâmica climática da área de estudo está relacionada com os sistemas secundários produtores de tempo, com destaque para: a Zona de Convergência Intertropical (ZCIT), a atuação da borda de Vórtices Ciclônicos de Altos 
Níveis (VCAN), Frentes Frias (FFs), Distúrbios Ondulatórios de Leste (DOLs) e Linhas de Instabilidades (Lls) e, excepcionalmente, a ação da Zona de Convergência do Atlântico Sul (ZCAS), que são mecanismos de Mesoescala (CAVALCANTI et al., 2009). Apresenta um clima quente e úmido em sua maioria, com precipitação anual média superior a $1.000 \mathrm{~mm}$ na Zona da Mata e de 600 a 800 mm no Agreste (CONDEPE/FIDEM, 2006).

\section{Base cartográfica}

Para o mapeamento hipsométrico da bacia do rio Una, utilizou-se o modelo digital do terreno (MDT), a partir das imagens do Advanced Land Observing Satellite (ALOS PALSAR), com resolução espacial de 20 metros, disponibilizadas no search.asf.alaska.edu. Para os mapas de detalhes das formas fluviais foi utilizado ortofotocartas com resolução espacial de $50 \mathrm{~cm}$, fornecidas pelo estado de Pernambuco, junto a Agência Pernambucana na Águas e Climas (APAC), através do projeto de levantamento aerofotogramétrico e perfilamento a Laser em todo território do estado de Pernambuco (PE3D).

As bases cartográficas dos municípios, estados e países foram aproveitadas do IBGE (2007). O processamento dos mapas foi gerado no software ArcGis 10.3 sendo executado a delimitação automática da bacia, a qual, posteriormente, foi corrigida com base no mapa de bacias hidrográficas disponibilizado pelo Governo do Estado de Pernambuco. A extração da rede de drenagem, a partir das ferramentas do ArcHydro.

\section{Mapeamento do confinamento de vale e das desconectividades}

Para o mapeamento de confinamento do vale, foi considerado a metodologia proposta por Brierley e Fryirs (2005), que seria os dos estilos fluviais. Está abordagem evidencia-se como principal objetivo uma análise integrada do domínio fluvial para fins de planejamento ambiental e territorial, importante ressaltar que nessa pesquisa foi utilizado apenas a primeira parte da tipologia dos estilos fluviais, que seria a delimitação dos tipos de confinamento de vale. Brierley e Fryirs (2005) determinaram três categorias de vale a partir da sua configuração: o confinado, o parcialmente confinado e o lateralmente não confinado (Figura 02).

Figura 2. A: vale confinado; B: vale parcialmente confinado e C: vale lateralmente não confinado

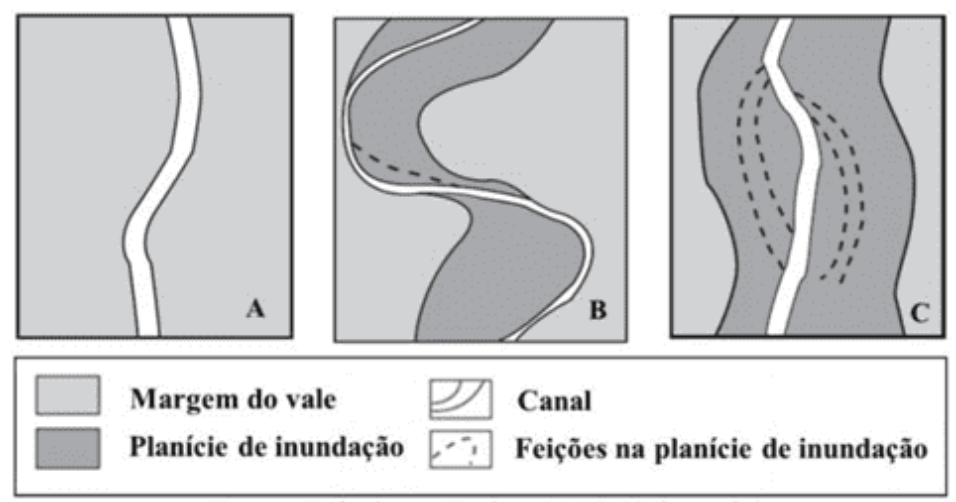

Fonte: Brierley e Fryirs, 2005 (Adaptado). 
Para determinar se o vale é confinado, parcialmente confinado ou lateralmente não-confinado, é necessário observar a presença ou ausência de planícies de inundação. Para o vale confinado a presença de planície de inundação é menor que $10 \%$ ou ausentes, no vale parcialmente confinado essa presença está entre $10-90 \%$ de planície de inundação descontínuas e os vales lateralmente não confinado mais de $90 \%$ da presença de planície de inundações contínuas (Figura 03).

Figura 3. Identificação dos estilos fluviais
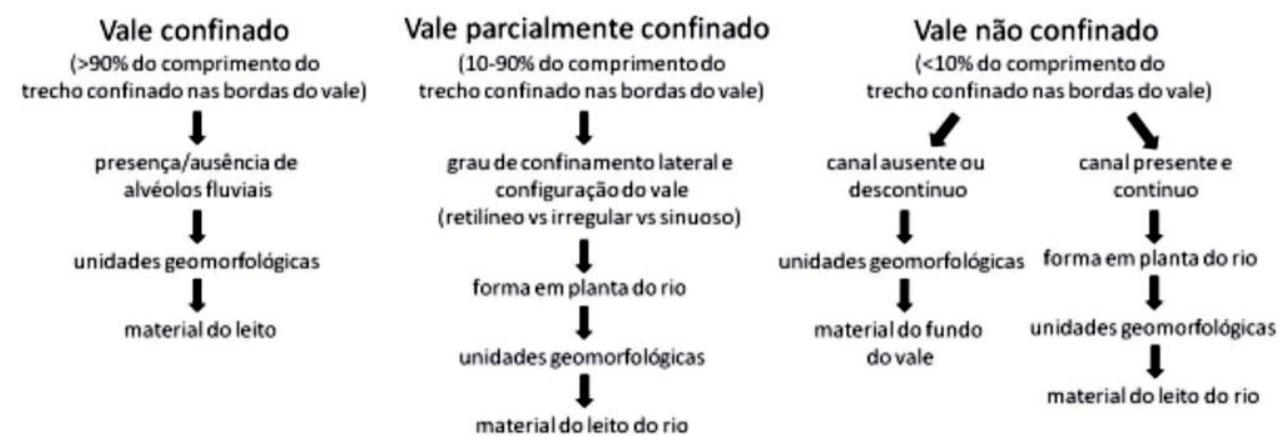

Fonte: Brierley e Fryirs, 2005.

Para a identificação do tipo de confinamento de vale utilizaram-se mapas-base de relevo sombreado, declividade e curvas de nível, gerados a partir do MDT ALOS no software ArcGis 10.3 para a delimitação das planícies de inundação, depois foram constatadas nas atividades de campo, no qual ocorreram em dois momentos, fevereiro/18 e maio/19.

A identificação e mapeamento das desconectividades antrópicas baseou-se na metodologia de Brierley e Fryirs (2005) e Fryirs et al. (2007a). Inicialmente buscou-se identificar as desconectividades partir de imagens de alta resolução do Google Earth Pro e do PE3D. O recorte de busca foi o baixo curso do rio Una, especificamente ao canal principal e a ligação final dos seus tributários ao mesmo. As principais desconectividades antrópicas encontradas nesse espaço delimitado foram as estradas não asfaltadas (buffers) e as pontes (barriers).

O mapeamento desses pontos de problemas da conectividade no sistema fluvial, relacionados a obstáculos de cunho antrópico foi realizado pelo software ArcGis 10.3. No qual foi realizado a fotointerpretação e marcação de pontos de controle das atividades antrópicas, sendo 87 pontos de estradas não asfaltadas e 06 pontes, que configuram elementos de desconexão no ambiente fluvial. Os dois trabalhos de campo validaram as informações verificadas em laboratório. 


\section{RESULTADOS E DISCUSSÃO}

A análise da bacia do rio Una ocorreu levando-se em consideração apenas o canal principal em termos de característica do confinamento de vale. A identificação dos depósitos fluviais ocorreu no baixo curso, o qual foi delimitado diante do trecho do canal lateralmente não confinado (Figura 4). A escolha desse trecho para ser detalhado no presente artigo dar-se-á devido sua configuração não-confinada, portanto, a capacidade de mutabilidade das formas e respostas diante dos inputs de matéria e energia é maior.

Segundo Brierley e Fryirs (2005) a configuração do vale exerce uma influência primária na morfologia dos canais fluviais, ou seja, a partir do padrão de confinamento do vale é possível ocorrer restrições nas formas e processos ao longo do canal. Para a bacia hidrográfica do rio Una (Tabela 1), no trecho da cabeceira de drenagem, que corresponde ao padrão confinado, com altitude entre 1179 a 414 metros, o canal passa encaixado nas paredes rochosas, o vale funciona como canal, o que dificulta os processos geomórficos. Porém, contribui em uma maior resistência aos ajustes lateral e vertical deste trecho, caracteriza-se como uma zonafonte de sedimentos, pela maior relação encosta-canal.

Figura 4. Mapa hipsométrico da bacia e confinamento de vale do rio Uma

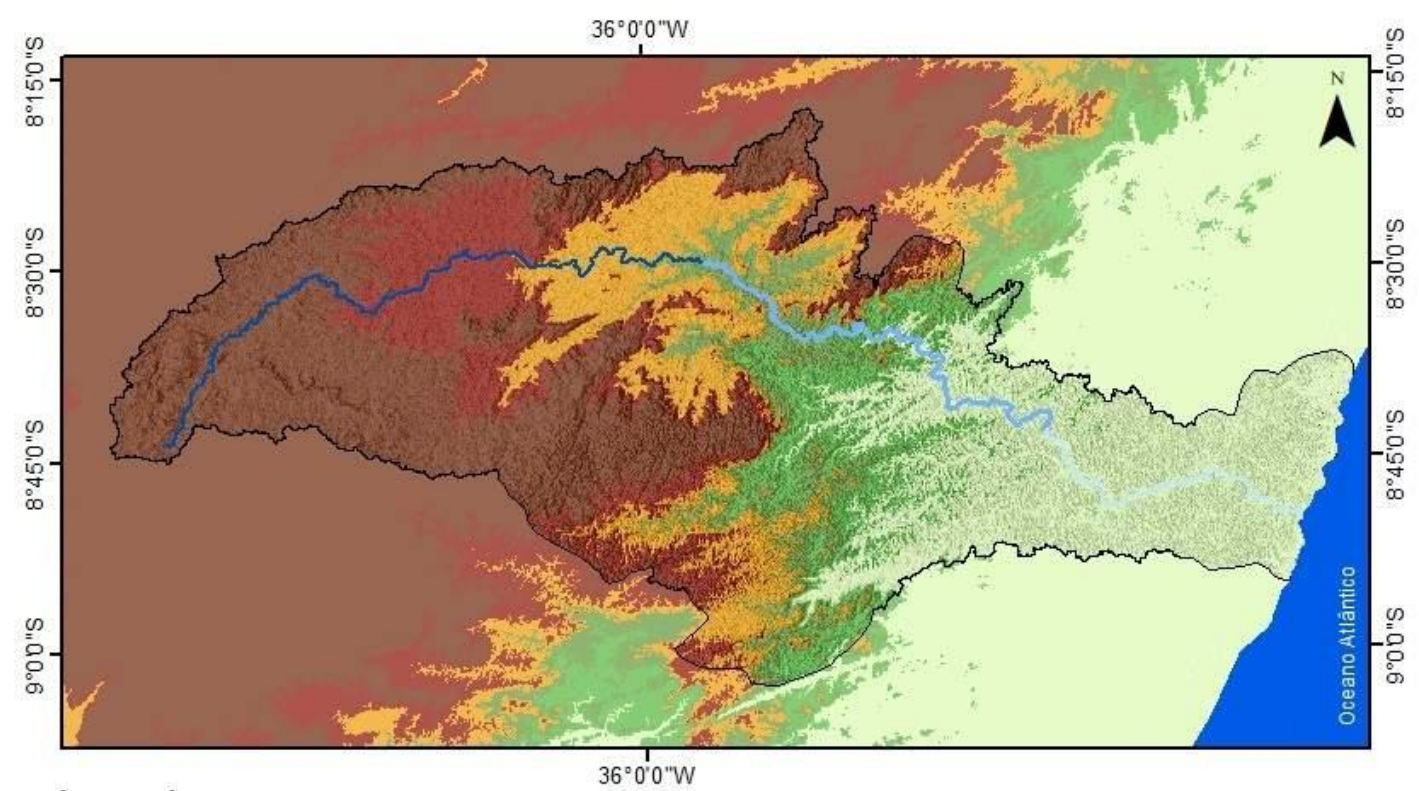

\section{Legenda}
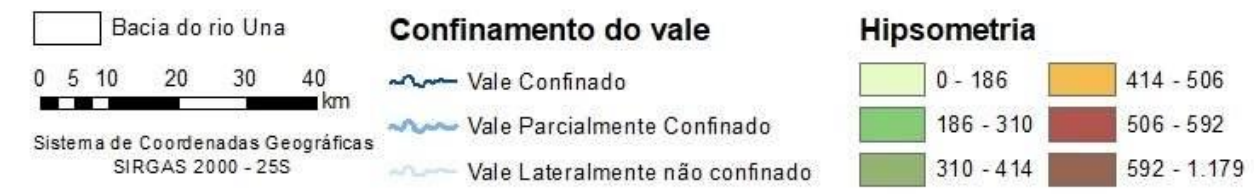

Fonte: Os autores. 
Tabela 1. Confinamento de vale do rio Uma

\begin{tabular}{lc}
\hline \multicolumn{1}{c}{ Tipos de vale } & Comprimento $(\mathbf{k m})$ \\
\hline Vale Confinado & 129,30 \\
Vale Parcialmente confinado & 90,77 \\
Vale Lateralmente não confinado & 55,07 \\
\hline Fonte: Os autores.
\end{tabular}

O padrão parcialmente confinado, nas altitudes de 414 a 186 metros, e o lateralmente não confinado, localizado em altitudes de até 186 metros, apresentam planícies de inundação em sua configuração, o que caracteriza uma menor resistência aos processos erosivos e a maior formação de unidades geomórficas ao longo do trecho. Segundo Brierley e Fryirs (2005), a formação da planície de inundação está associada à largura do vale. Nos vales mais largos, a energia do rio é dissipada, podendo reduzir os picos de descarga a depender do evento, para os vales estreitos, ocasiona maior fluxo de corrente e extravasamento lateral e vertical do canal.

No trecho lateralmente não confinado, a planície de inundação apresenta-se continua ao longo do vale. Estas áreas possuem um relevo rebaixado e são caracterizadas como ambiente de acumulação de sedimento, contribuindo na formação de depósitos fluviais. Diante disso, o presente trabalho estuda o baixo curso do rio Una por estar compreendido na configuração de vale lateralmente não confinado, possibilitando identificar os ambientes de deposição e as principais formas geradas por este processo.

O baixo curso do rio foi identificado a partir da configuração do vale, portanto definido sobre o trecho de vale lateralmente não confinado cujas características morfológicas, atreladas ao contexto climático, possibilitam a deposição de sedimentos nos espaços de acomodações.

A porção sul de Pernambuco, onde se encontra a bacia em estudo, caracteriza-se, climaticamente, por sofrer ações de dinâmicas climáticas pluviais, principalmente, durante o outono-inverno, como as DOLs (Distúrbios Ondulatório de leste $)^{1}$ que possibilitam possíveis processos de ajustes e deposição que se configuram em morfologias fluviais típicas de áreas de topografia menos declivosa em climas tropicais úmidos. É importante, segundo Brierley e Fryirs (2013), que as mudanças no padrão das assembleias morfológicas fluviais em relação à erosão/deposição ocorram a partir de fatores tectônicos, climáticos e/ou antrópicos.

O trecho representado no padrão do canal neste segmento é sinuoso (Figura 5), e apresenta uma planície de inundação contínua com variação de altitude de até 186 metros, apresentando dois meandros abandonados. Devido ao padrão sinuoso e de baixa energia ocorre a presença de uma barra longitudinal, denotando uma morfologia fluvial significativa.

\footnotetext{
${ }^{1}$ As ondas de leste ou Distúrbios de Ondulatório de Leste segundo Varejão-Silva (2006) são perturbações atmosféricas que ocorrem nos trópicos sob a forma de conglomerados de nuvens convectivas. Se deslocam de leste para oeste acompanhando um cavado barométrico. É a dinâmica atmosférica mais recorrente durante o período chuvoso na porção leste da Região Nordeste, principalmente atuando sobre o litoral e Zona da Mata dos Estados da PB, PE e AI.
} 
Os meandros abandonados estão em locais alagados da planície de inundação, os quais indicam que nos períodos de maior entrada de energia e matéria sobre o canal estas áreas são inundadas e os sedimentos depositados. Percebe-se indícios da existência pretérita neste trecho de um padrão de duplo canal, acompanhado por barras longitudinais (Figura 06). Tendo em vista a dinâmica morfológica fluvial, a qual conduziu ao abandono de parte do canal secundário que se encontra atualmente quase todo preenchido por sedimentos, modificou-se a conexão com o canal principal, cuja barra longitudinal foi alterada para barra lateral.

Observa-se que o meandro destacado tem como uso o acesso de caminhões no processo de retirada de areia que geralmente é destinada à construção civil. A população local se aproveitou desta morfologia para acessar o leito do rio Una para extração de sedimentos.

Figura 5. Trecho sinuoso com presença de meandros abandonados, barras longitudinais e planícies de inundação contínuas no baixo rio Uma

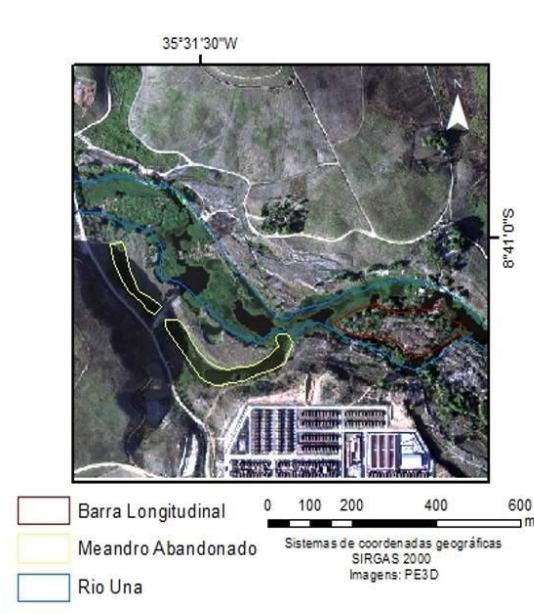

Fonte: Os autores.

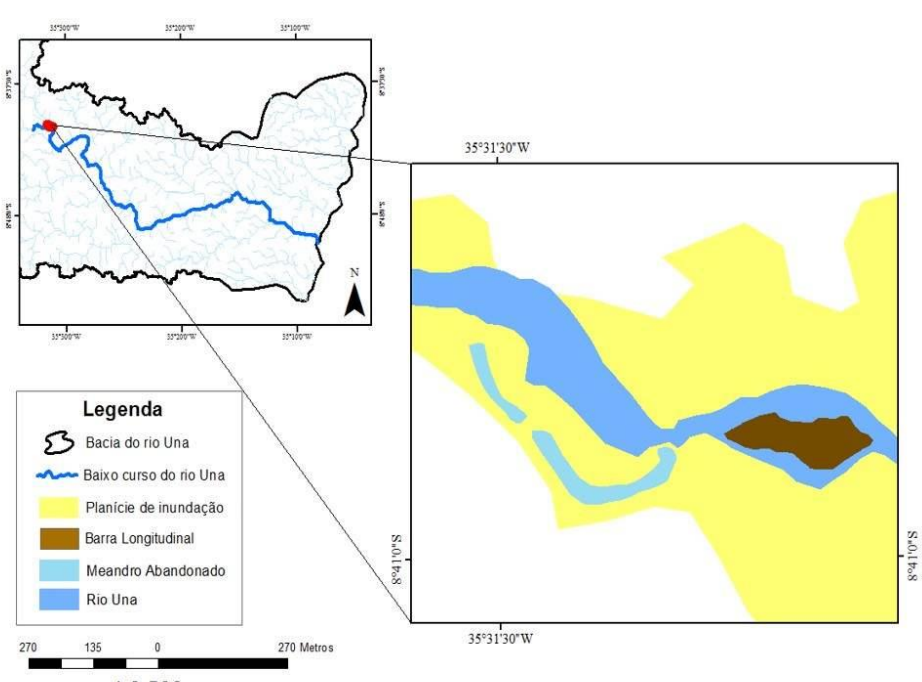

1:6.532

Figura 6. Trecho de meandro abandonado. As setas azuis representam a direção do fluxo, enquanto a seta marrom representa a área de retirada de sedimentos

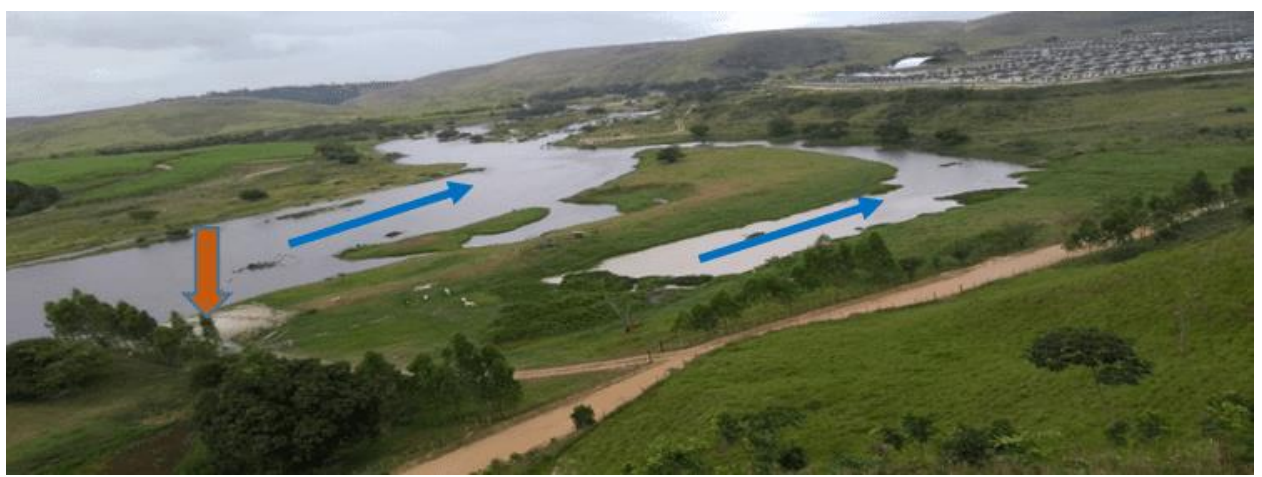

Fonte: Os autores. 
Ao prosseguir no baixo curso do rio Una, o segundo trecho (Figura 07), caracteriza-se por ser sinuoso com presença de planície descontínua e a ocorrência de barras laterais. Uma das margens não apresenta planície de inundação, configurando maior conexão da encosta com o canal fluvial. Posteriormente, a planície de inundação, em seguida, forma um espaço de acomodação de sedimentos após o trecho de planície descontínua.

Figura 7. Trecho sinuoso com presença de Barras Laterais e planícies de inundação descontínuas
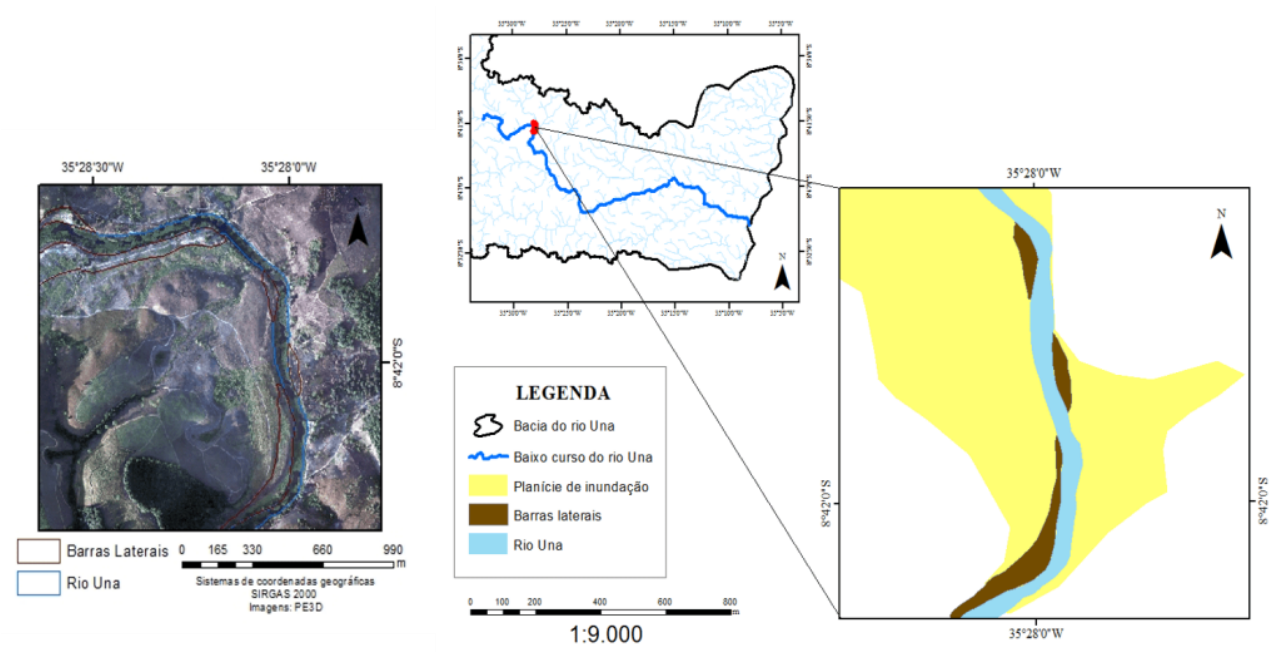

Fonte: Os autores.

Embora parcialmente vegetadas, as barras laterais consistem em produtos de processos de passado relativamente recente que são característicos de segmentos parcialmente não confinados por conseguinte, esses materiais estão sujeitos a retrabalhamento diante de um evento de alta magnitude.

Sobre estas barras, os processos erosivos ocorrem pela capacidade de ajuste do canal diante de entradas de energia e matéria que chegam ao limiar do sistema. Portanto, os sedimentos destes depósitos são em geral incoesos e facilmente removidos devido a sua granulometria arenosa, e ainda por se tratar de material já retrabalhado, o que favorece a ação dos processos erosivos. Por apresentarem vegetação incipiente, estas barras tendem a ter maior resistência as ações erosivas.

No terceiro segmento (Figura 08) no baixo curso do rio Una apresenta leques, os quais se configuram sobre trechos finais de tributários. Portanto, apoiado na confluência dos canais tributários, os espaços de acomodação criados em uma área de vale lateralmente não confinado e os leques aluviais, segundo Morais e Rocha (2016), são gerados pelo fluxo de sedimentos de afluentes, sobre as unidades de planície de inundações e terraços. 
Figura 8. Trecho com canais tributários, bacias de inundação e presença de leques fluviais.
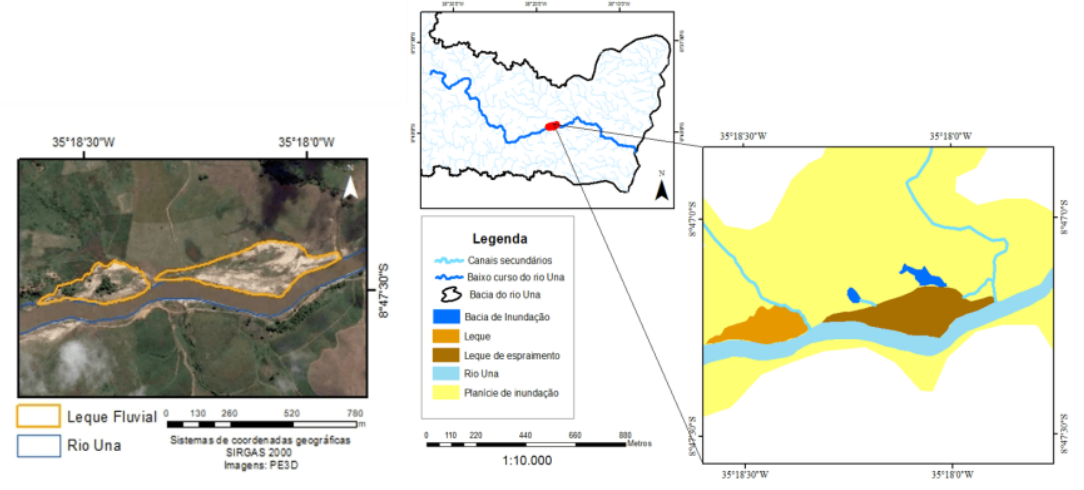

Fonte: Os autores.

O leque destacado na Figura 8 encontra-se parcialmente vegetado. Todavia, grande parte da respectiva unidade geomorfológica tem seus sedimentos arenosos incoesos e expostos aos processos erosivos. Estes sedimentos incoesos indicam deposição recente. Constata-se uma estratificação cruzada referente a deposição do leque (em marrom mais claro na figura 08) de um afluente de pequeno porte que se conecta com o rio Una (Figura 09). Esta morfologia é típica em tais ambientes fluviais.

Figura 9. Leque fluvial resultado da confluência de um afluente com o rio Uma

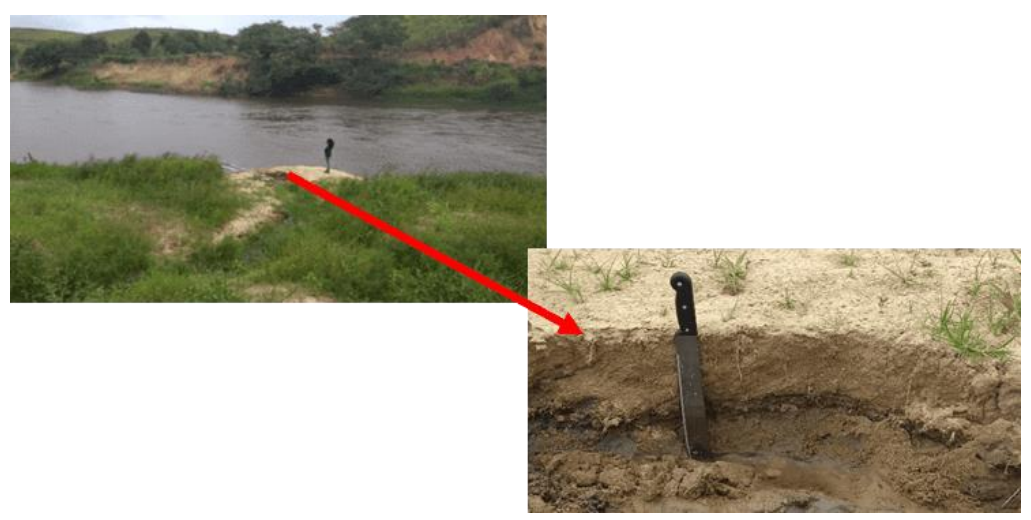

Fonte: Os autores.

Já o leque de espraiamento foi identificado devido à discordância da deposição dos sedimentos em comparação com a planície de inundação, constitui-se em uma morfologia composta por materiais arenosos aparentes e com incipiente processo de disseminação de cobertura vegetal natural. Os sedimentos incoesos estão sujeitos a ajustes erosivos, contudo indicam a incapacidade fluvial de remover o material inconsolado.

A bacia de inundação que está localizada na planície distal configura-se, segundo Brierley e Fryirs (2013), como típicos de áreas de baixa declividade e apresentam-se como unidades de armazenamento de sedimentos finos devido à carga suspensa. Para Morais e Rocha (2016) esta unidade geomórfica indica áreas mais antigas 
de abandono de canal, delineadas pela umidade, obliteradas pela dinâmica da planície e consequentes amorfas. As bacias de inundações mapeadas neste trecho do baixo curso do rio Una apontam uma mudança na morfodinâmica do canal principal e seus tributários, assim como, uma determinada conectividade dos fluxos em períodos de inundação.

O quarto segmento exibe um canal anastomosado, com presença de ilhas fluviais vegetadas. A maior destas ilhas apresenta morfologia típica desta unidade geomórfica, com indicação de baixa energia, ou seja, de fluxo fluvial de pouca competência para remover os sedimentos. Estes são depositados em camadas geradoras de barras longitudinais que, posteriormente, com a disseminação da vegetação, torna-se uma ilha fluvial.

Portanto, as ilhas demonstram que este trecho se encontra com mais estabilidade no que se refere a processos erosivos, principalmente pela presença da vegetação, que a partir do suporte mecânico do sistema radicular, propiciam agregação dos sedimentos, criando resistência ao processo de desgaste erosivo.

Ademais, de acordo com Brierley e Fryirs (2013), a cobertura vegetal aumenta as taxas de deposição, promovendo um acréscimo vertical dos sedimentos. Desta forma, quando as barras longitudinais são colonizadas por vegetação, esta conduz a estabilidade, levam a evolução das barras em ilhas.

Nos trechos do baixo curso do rio Una ocorre vários segmentos anastomosados (Figura 10) com múltiplos canais rasos com barras e ilhas, que podem ser recobertas ou não em período de maior entrada de energia.

Figura 10. Morfologias de trecho anastomosado, com presença de ilhas fluviais no baixo curso do rio Una

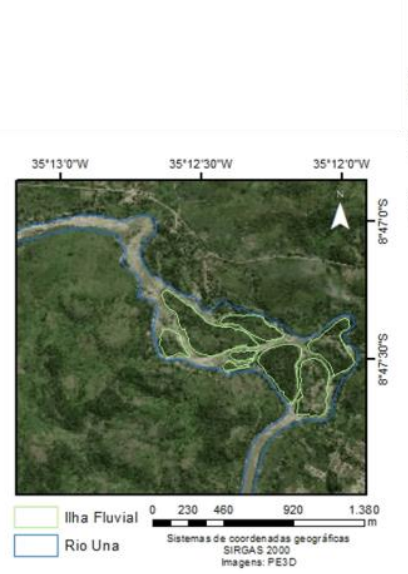

Fonte: Os autores.

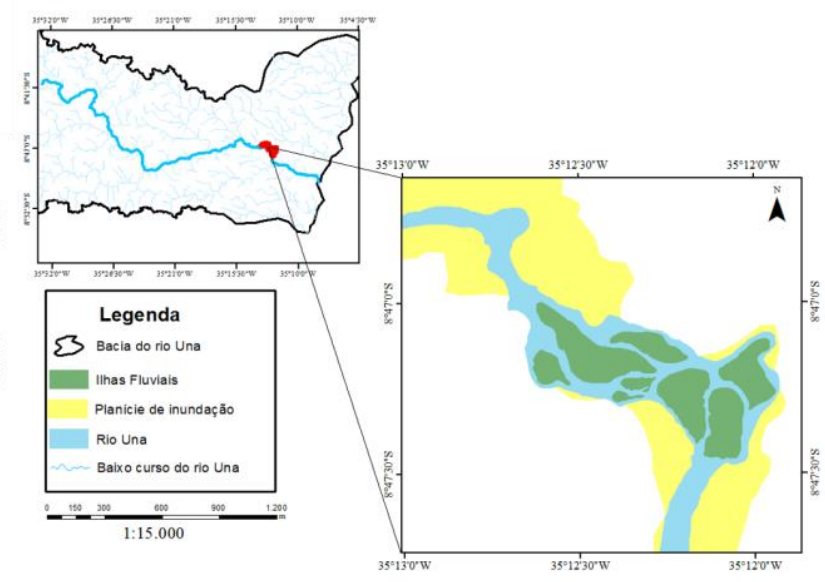

Os depósitos fluviais são criados em espaços de acomodação que podem ser de origem tectônica, climática ou antrópica. Diante disso, os elementos de desconectividades antrópicas podem colaborar na 
formação destas feições fluviais. Isto dar-se devido aos impedimentos impostos pelo uso e ocupação da terra, através de pontes e barreiras diversas, entre outras que dificultam o fluxo de sedimento no sistema fluvial.

\section{Desconectividades antrópicas no Baixo Curso}

A conectividade se desenvolve quando ocorre a transmissão, sem interrupções, de energia e matéria dentro de uma paisagem considerada. Esta ligação pode vir a sofrer impedimentos provenientes de processos naturais presentes na paisagem. Ocorre ainda, barramentos da transmissão de energia e matéria por ações humanas, criando, de forma artificial, modificações na dinâmica de fluidez em um espaço de domínio fluvial, por exemplo. As atuações antrópicas repercutem de maneira abrangente in situ e nas adjacências, devido à interligação do sistema.

O baixo curso do rio Una possui alguns problemas da conectividade no sistema fluvial, relacionados a obstáculos de cunho antrópico. Dando um enfoque maior ao canal principal e a ligação final dos seus tributários com o rio Una, verificou-se duas desconectividades antrópicas principais (Figura 11) denominadas e correlacionadas com as tipologias de Brierley e Fryirs (2005) e Fryirs et al. (2007a): estradas não asfaltadas (buffers) e pontes (barriers). Os primeiros impedem a entrada de sedimentos nos canais por estarem cortando o final dos afluentes próximo à chegada no rio Una, já as pontes ocasionam bloqueios, constituídos dentro dos canais pela estrutura das colunas de sustentação.

Figura 11. Mapa das desconectividades antrópicas no baixo curso do Rio Uma

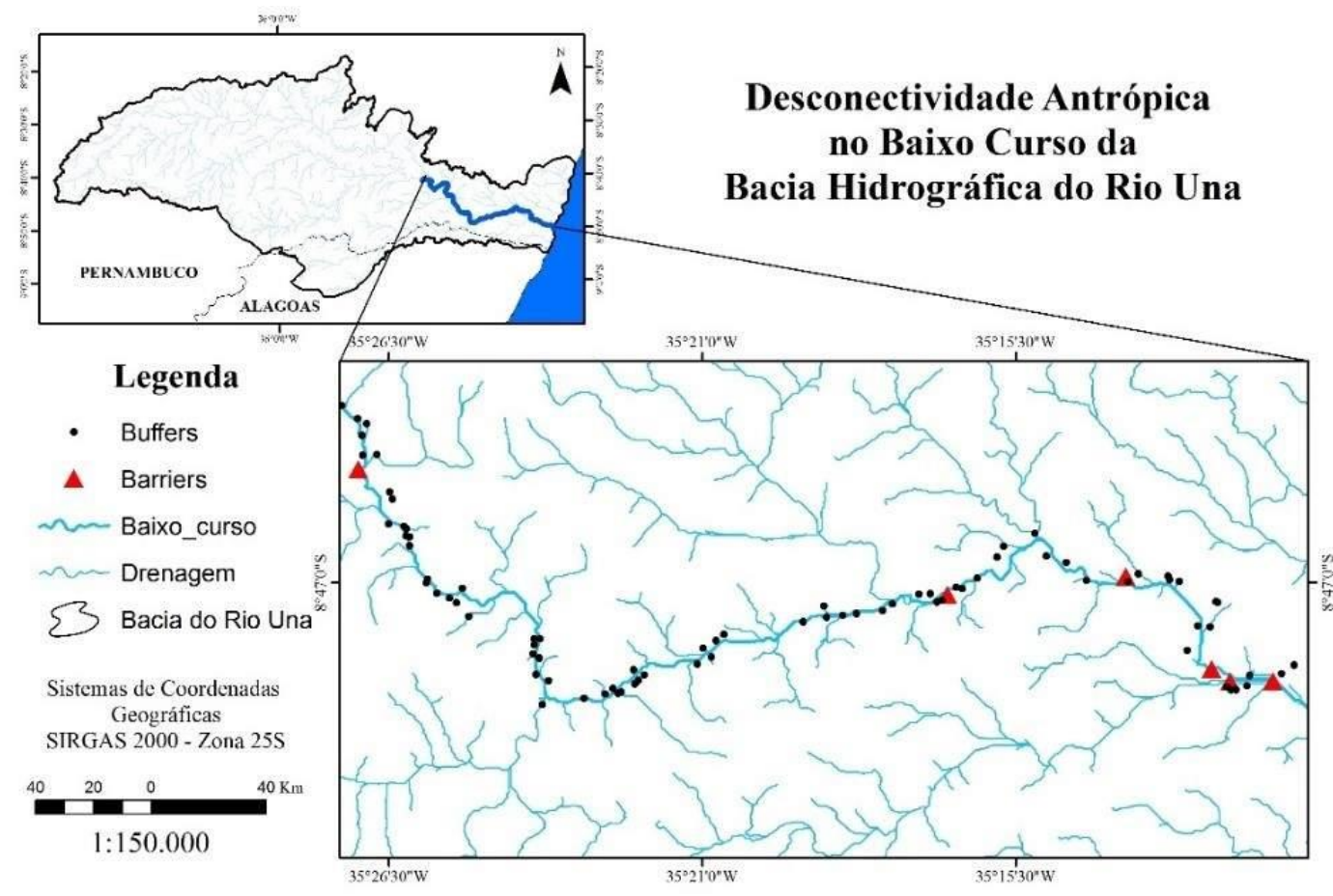

Fonte: Os autores. 
A existência das estradas não asfaltadas de maneira paralela ocorre de forma constante em todo o baixo curso do rio Una (Figura 12), onde foram encontrados 87 pontos distribuídos no baixo curso. A desconectividade ocorre por estradas não asfaltadas que cortam os cursos fluviais tributários, impedindo, de maneira transitória, que os sedimentos e as águas cheguem no canal principal.

Esta interferência humana pode levar a mudanças no leito do canal principal do rio Una, através, por exemplo, dos processos erosivos ou não deposicionais, devido à ausência de material no leito principal. Fator este que interfere sobre o confinamento do vale, a planta do canal, as unidades geomórficas e a textura do leito do sistema fluvial, que podem ser alteradas por aumento ou diminuição dos processos erosivos no canal.

Figura 12. Mapeamento dos buffers no baixo curso do Rio Uma

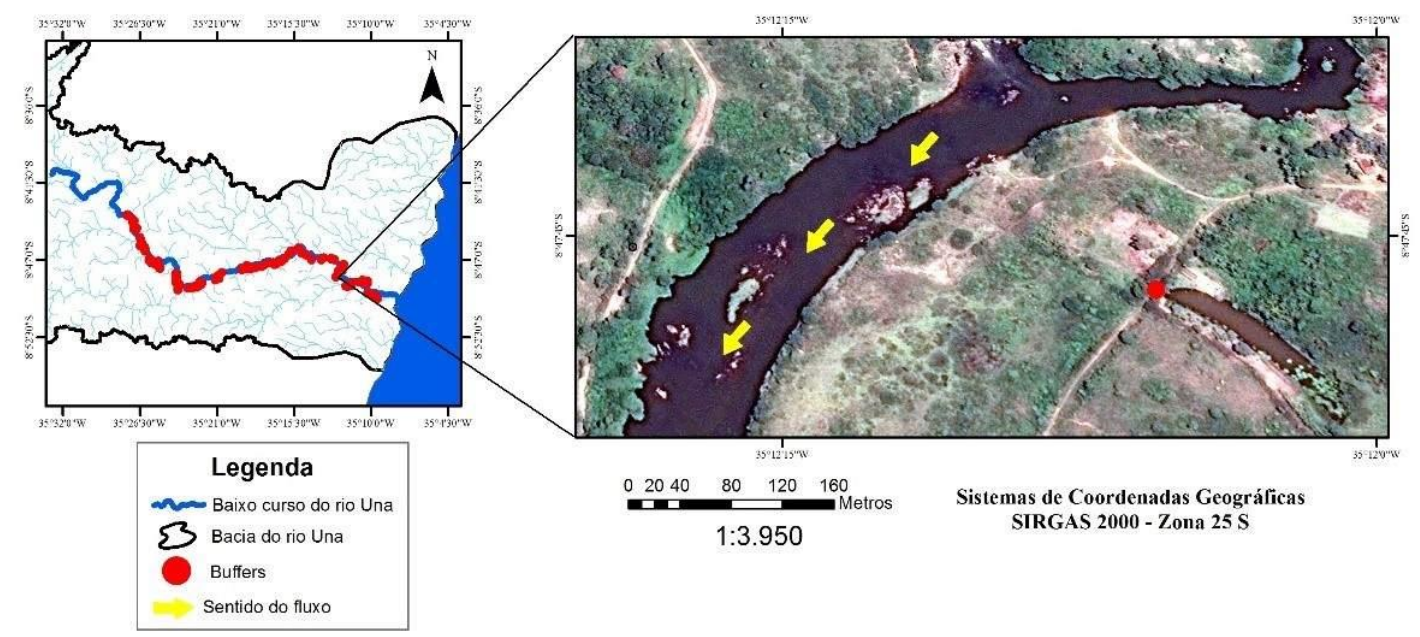

Fonte: Os autores.

As pontes, diferentemente das estradas não asfaltadas, obstruem o fluxo com suas colunas de sustentação edificadas dentro do canal. Neste contexto, não existem um impedimento por completo dos sedimentos e água presentes no canal. Contudo, em momentos de inputs de energia e material, quando de eventos pluviais extremos, tais estruturas artificiais modificam o processo natural das unidades geomórficas e da textura do leito através do aumento da vazão e mesmo da agregação de elementos sólidos ao fluxo. No baixo curso do rio Una foram encontradas seis pontes (Figura 13), sendo cinco delas ligadas a estradas asfaltas e uma ligando a margem esquerda do canal a uma ilha fluvial de construção caseira conectada a uma estrada não asfaltada. 
Figura 13. Mapa das Barriers no Baixo curso do rio Una

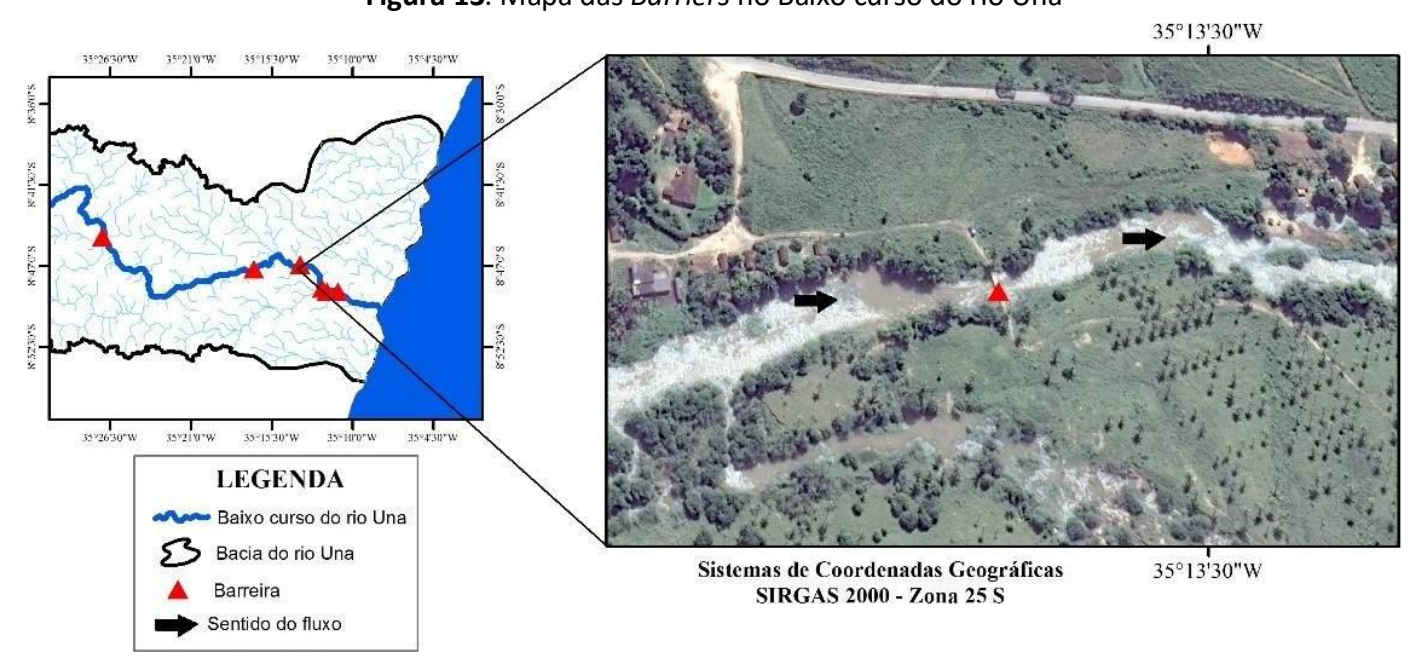

Fonte: Os autores.

As desconectividades encontradas no baixo curso do rio Una dentro do canal (pontes) e no final dos seus tributários (estradas não asfaltadas) podem alterar a montante e a jusante o equilíbrio dinâmico fluvial, principalmente rompendo a conectividade de sedimentos que chegam até o canal e ficam retidos nessas áreas. Logo, contribuindo para formação de novos níveis de base e para o extravasamento lateral do fluxo.

Todavia, essa conectividade pode ocorrer novamente de maneira plena caso ocorra um aumento da magnitude e/ou frequência de energia e matéria no sistema. Isto é, por exemplo, quando de uma precipitação de alta intensidade e baixa recorrência levar buffers a se romperem retomando a conexão com o canal principal, e os barriers a serem destruídos pela maior proporção de água e sedimentos no canal.

Por conseguinte, haveria uma retomada da harmonia processual da dinâmica do canal, levando a identificação de três equilíbrios dinâmicos no sistema fluvial: 1. O primeiro ocorreu antes das desconectividades; 2 . O segundo durante a interferência antrópica; 3. O terceiro após a nova conectividade.

Assim, a conectividade e desconectividade pode ocorrer em uma escala temporal não precisa, visto que o equilíbrio na natureza é complexo e dinâmico, mesmo tendo a paisagem sido alterada pelo agente antrópico em período curto de tempo.

\section{CONSIDERAÇÕES FINAIS}

A identificação constitui o processo inicial dos estudos em geomorfologia fluvial. Portanto, a partir do reconhecimento destas feições geomórficas tem-se a compreensão das dinâmicas ocorridas no determinado trecho de um canal fluvial. No caso do presente artigo, que compreende o baixo curso do rio Una, as áreas 
representativas destacadas indicaram os processos atuantes recentes que configuram a morfologia do canal principal.

As análises condizentes com a morfologia de canais, processos deposicionais, configuração de vale e (des)conectividades ainda são pouco abordadas, sobretudo sobre os rios de ambientes tropicais úmidos. 0 estudo procurou contribuir, inicialmente, com o entendimento dos processos deposicionais no baixo curso do rio Una, assim como, com configuração do vale lateralmente não confinado em uma perspectiva atrelada as morfologias fluviais.

Entender, mesmo que preliminarmente, o comportamento da morfodinâmica e morfogênese fluvial, como também as (des)conectividades que modificam o transporte de energia e matéria, se constitui em fator relevante para ações voltadas para o planejamento e gestão, seja do ponto de vista ambiental e/ou territorial, dos ambientes fluviais.

A continuidade das pesquisas de cunho fluvial na bacia hidrográfica do Una torna-se imprescindível no intuito de aprimoramento da compreensão dos processos atuantes sobre o canal principal. As análises advindas da Geomorfologia Fluvial é uma excelente ferramenta para tomada de decisão de políticas de planejamento e gerenciamento, trazendo a dinâmicas geomórficas para o centro do estudo, correlacionando com os dados hidrológicos trabalhados pelos engenheiros.

\section{REFERÊNCIAS}

APAC. Agência Pernambucana de Águas e Clima. Bacia do Rio Una. Disponível em:

http://www.apac.pe.gov.br/pagina.php?page_id=5\&subpage_id=23. Acesso em 22/06/2017.

BLANTON, P.; MARCUS, W. A. Railroads, roads and lateral disconnection in the river landscapes of the continental United States. Geomorphology, v. 112, 2009, p. 212-227.

BRACKEN, L. J.; et al. Sediment connectivity: a framework for understanding sediment transfer at multiples scales. Earth Surf. Process. Landforms, 40, 2015, p. 177-188.

BRIERLEY, G. J.; FRYIRS, K. A. Geomorphic analysis of river systems: an approach to reading the landscape. $1^{\circ}$ ed, Blackwell Publishing Ltd, 2013, 360p.

BRIERLEY, G. J.; FRYIRS, K. A. Geomorphology and River Management Applications of the River Styles Framework. $1^{\circ}$ ed, Blackwell Publishing Ltd, 2005, 412p.

BRIERLEY, G.; FRYIRS, K.; JAIN, V. Landscape connectivity: the geographic basis of geomorphic applications. Area (2006) 38.2, p. 165174.

BRUNSDEN, D. A critical assessment of the sensitivity concept in geomorpholog. Catena, v. 42, n. 2-4, 2001, p. 99-123.

BRUNSDEN, D.; THORNES, J. B. Landscape Sensitivity and Change. Transactions of the Institute of British Geographers, New Series, v. 14 , n. 4, 1979, p. 463-484.

CAVALCANTI, I. F. A, FERREIRA, NELSON J. DIAS, M. ASSUNÇÃO F. da SILVA, SILVA, M. GERTRUDES A. JUSTI da. Clima e Tempo no Brasil. São Paulo: Oficina de Textos, 2009, 463p.

CHRISTOFOLETTI, A. Geomorfologia Fluvial. São Paulo: 1o Reimpressão, Ed. Edgar Bluncher Ltda, 1981, edição 2009, 464p. 
CHISTOFOLETTI, Antônio. Modelagem de Sistemas Ambientais. Ed. Edgard Blücher, $1^{\circ}$ ed, São Paulo, 1999, 236p.

CONDEPE/FIDEM. Agência Estadual de Planejamento e Pesquisas de Pernambuco. Bacia Hidrográfica do Rio Una, Quarto e Quinto Grupos de Bacias Hidrográficas de Pequenos Rios Litorâneos - GL 4 E GL 5. Série Bacias Hidrográficas de Pernambuco no 3. Recife: $2006,85 \mathrm{p}$.

DREW, D. Processos interativos homem-meio ambiente. 6. ed. Rio de Janeiro: Bertrand Brasil, 2005. 206p.

EMBRAPA. Empresa Brasileira de Pesquisa Agropecuária. Sistema brasileiro de classificação de solos. Rio de Janeiro: EMBRAPA/CNPS, $3^{\circ}$ ed. 2013. 353p.

FRYIRS, K. (Dis) Connectivity in catchment sediment cascades: a fresh look at sediment delivery problem. Earth Surface Process and Landforms, v. 38, 2013, p. 30-46.

FRYIRS, K. A.; BRIERLEY, G. J. Geomorphic Analysis of River Systems: an approach to reading the landscape. Blackwell Publishing LTD, 1ㅡ. Ed., 2013. 327p.

FRYIRS, K. A.; et al. Buffers, barriers and blankets: the (dis)connectivity of catchment-scale sediment cascades. Catena, v. 70, 2007a, p. 49-67.

HARVEY, A. M. Coupling between hillslopes and channels in upland fluvial systems: implications for landscape sensitivity, illustred from the Howgill Fells, northwest England. Catena, n. 42, 2001, p. 225-250.

HARVEY, A. M. Effective timescales of coupling within fluvial systems. Geomorphology, v. 44, 2002, p. 175-201.

HARVEY, A. M. The coupling status of alluvial fans and debris cones: a review and synthesis. Earth Surface Processes and Landforms, v. 37,2012, p. 64-74.

HOOKE, J. Coarse sediment connectivity in river channel systems: a conceptual framework and methodology. Geomorphology, v. 56, 2003, p. 79-94.

KASAI, M. et al. Impacts of land use change on patterns of sediment flux in Weraamaia catchment, New Zealand. Catena, v. 64, 2005, p. 27-60.

LIMA, Raphael Nunes de Souza; MARÇAL, Mônica dos Santos. Avaliação da Condição Geomorfológica da Bacia do Rio Macaé - RJ a partir da metodologia de Classificação dos Estilos Fluviais. Revista Brasileira de Geomorfologia, v. 14, no 2, Abr/Jun, 2013, p. 171179.

MORAES NOVO, E. M. L. Ambientes fluviais. In: FLORENZANO, T.; Geomorfologia - conceitos e tecnologias atuais. Oficina do Texto: São Paulo, 2008, 318p.

MORAIS, E. S.; ROCHA, P. C; Formas e processos fluviais associados ao padrão de canal meandrante: o baixo rio do Peixe, SP. Revista Brasileira de Geomorfologia, v. 17, no 3, 2016, p. $431-449$.

SCHUMM, Stanley A. The Fluvial System. Caldwell, The Blackburn Press, 1977, 337p.

SILVA, Adriana Cassiano da.; SILVA, Osvaldo Girão da. Analises dos padrões e estilos de canais a partir da paisagem geomorfológica fluvial na bacia do rio Una/PE. Revista Cerrados - Montes Claros/MG, v.14, n. 2, jul/dez-2016, p.71-92.

SOUZA, J. O. P. Modelos de Evolução da Dinâmica Fluvial em Ambiente Semiárido - Bacia do Riacho do Saco, Serra Talhada, Pernambuco. Tese (Doutorado), 190f: Universidade Federal de Pernambuco, Programa de Pós-Graduação em Geografia, 2014.

SOUZA, Jonas Otaviano Praça de. BRIERLEY, G. J.; FRYIRS, K. A. Geomorphology and river management: applications of the river styles framework. Victoria: blackwell publishing (commerce place, 350 main street, malden, MA02148, USA), 2005. 398P, Revista de Geografia (UFPE) V. 29, No. 2, Mar, 2012, p. 252-259.

ROCHA, P. C.; SOUZA FILHO, E. E.; Interações dinâmicas entre os materiais do leito de um canal secundário com o canal principal no trecho multicanal do Alto Rio Paraná, Brasil. Revista Brasileira de Geomorfologia - Ano 6, 2005, p. 19-32.

THOMAS, M. F. Landscape sensitivity in time and space - an introducion. Catena, v. 42, 2001, p. 83-98.

VAREJÃO-SILVA, M. A. Meteorologia e climatologia. Versão digital 2. Recife 2006. 